\title{
Nature and frequency of medication errors in a geriatric ward: an Indonesian experience
}

\author{
Desak Ketut Ernawati ${ }^{1,2}$ \\ Ya Ping Lee ${ }^{2}$ \\ Jeffery David Hughes ${ }^{2}$ \\ 'Faculty of Medicine, Udayana \\ University, Denpasar, Bali, Indonesia; \\ ${ }^{2} \mathrm{School}$ of Pharmacy and Curtin \\ Health Innovation and Research \\ Institute, Curtin University, Perth, \\ WA, Australia
}

Video abstract

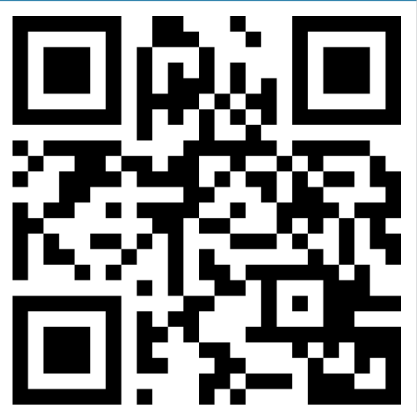

Point your SmartPhone at the code above. If you have a QR code reader the video abstract will appear. Or use: http://dvpr.es/ljoRrl8
Correspondence: Desak Ketut Ernawati Faculty of Medicine, Udayana University, Jalan PB Sudirman, Denpasar, Bali, Indonesia 80232

Phone +62361222510

Fax +62 36I 246656

Email desak.ernawati@postgrad.curtin. edu.au
This article was published in the following Dove Press journal:

Therapeutics and Clinical Risk Management

3 June 2014

Number of times this article has been viewed

Purpose: To determine the nature and frequency of medication errors during medication delivery processes in a public teaching hospital geriatric ward in Bali, Indonesia.

Methods: A 20-week prospective study on medication errors occurring during the medication delivery process was conducted in a geriatric ward in a public teaching hospital in Bali, Indonesia. Participants selected were inpatients aged more than 60 years. Patients were excluded if they had a malignancy, were undergoing surgery, or receiving chemotherapy treatment. The occurrence of medication errors in prescribing, transcribing, dispensing, and administration were detected by the investigator providing in-hospital clinical pharmacy services.

Results: Seven hundred and seventy drug orders and 7,662 drug doses were reviewed as part of the study. There were 1,563 medication errors detected among the 7,662 drug doses reviewed, representing an error rate of $20.4 \%$. Administration errors were the most frequent medication errors identified (59\%), followed by transcription errors (15\%), dispensing errors (14\%), and prescribing errors (7\%). Errors in documentation were the most common form of administration errors. Of these errors, $2.4 \%$ were classified as potentially serious and $10.3 \%$ as potentially significant.

Conclusion: Medication errors occurred in every stage of the medication delivery process, with administration errors being the most frequent. The majority of errors identified in the administration stage were related to documentation. Provision of in-hospital clinical pharmacy services could potentially play a significant role in detecting and preventing medication errors.

Keywords: geriatric, medication errors, inpatients, medication delivery process, Indonesian hospital

\section{Introduction}

The safe use of medications is crucial in health care services. Medication errors may occur at any stage of the medication delivery process. In the United States of America, an estimated 98,000 deaths per year are associated with medical errors, and medication errors account for approximately 10\%-20\% of total fatalities associated with medical errors. ${ }^{1,2}$ The Institute of Medicines reports that "on average a hospital patient is subject to at least one medication error per day" in the United States of America. ${ }^{3}$ Medication error is an important issue, but error rates are often reported differently. For example, they are reported based on drug doses, total admissions, or total opportunities for error. In a systematic review of 45 studies, Lisby et al found that there were 26 different definitions used to describe medication errors. ${ }^{4}$ They identified the majority of definitions used in the literature were based on the National 
Coordinating Council for Medication Error Reporting and Prevention definition. ${ }^{5}$ Further, Lisby et al found that less than $50 \%$ of the studies in their review defined medication errors based on stages in the medication delivery process. These stages include prescribing, transcribing, dispensing, and administration. ${ }^{4}$ Similarly, Pintor-Mármol et al found in their review that over the period of 1998-2008, there were almost 200 different definitions used to describe patient safety in relation to medication use. ${ }^{6}$

In the literature, medication errors have been conceptualized based on causes, outcomes, and stages of the medication delivery process. ${ }^{4,7,8}$ Determining the causes and outcomes of medication errors is necessary to find the sources and consequences of errors. However, identifying medication errors during the medication delivery process is also important. This is because health care professionals, the health system, as well as patients may contribute to medication errors in the process. In addition, health care providers involved in the medication delivery process may have different skills and training. The Joint Commission identified lack of training and communication failures as important causes of medication errors. ${ }^{9}$ Although limited studies have reported on medication safety in Indonesia, Alfansi and Atmaja, who studied service failures in an Indonesian hospital, stated that the quality of health care services in the country was poor. ${ }^{10}$ In addition, Perwitasari et al found that prescribing errors were common in outpatient clinics in one Indonesian hospital. ${ }^{11}$ They recommended that pharmacists have a role in reducing medication errors. The current study was therefore undertaken to determine the nature of medication errors occurring during the medication delivery process in a geriatric inpatients ward in a public hospital in Bali, Indonesia.

\section{Methods}

\section{Study design and patient population}

This was a prospective study conducted in a 13-bed geriatric ward of a public teaching hospital, in Bali, Indonesia. The patients recruited into the study were those aged $\geq 60$ years, who did not have a primary diagnosis of malignancy, were not undergoing surgery, or receiving chemotherapy, and who were willing to participate in the study. In the ward where the study was undertaken, the protocol for the medication delivery process was that the physician is responsible for writing the medications administered in patients' progress notes, medication charts, and in drug order forms. However, in most instances, nurses would transcribe the medications ordered in patients' progress notes onto medication charts and drug order forms. The drug order form is the primary form used to order medication from the central pharmacy in the hospital. Additional medications required after the physician visits the ward are ordered by phone or on a temporary drug order form. The central pharmacy dispenses medication orders based on the drug order form. The pharmacist on the ward dispenses medications in unit dose packaging based on medication charts. Nurses document the administration of oral dosages on medication charts, and record injectable medications in a nurse's log book.

The present study was conducted over a period of 20 weeks from February through July 2013, during which time the primary investigator provided clinical pharmacy services to the study ward. It should be noted that such services are not routinely provided within the study hospital.

\section{Data collection and medication error classification}

The primary investigator undertook training in hospitals in both Perth, WA, Australia and Jakarta, Indonesia prior to commencing data collection to obtain a clear insight into the medication delivery process and the delivery of clinical pharmacy services. Medication errors were identified through the delivery of clinical pharmacy services (see next paragraph). The error classification system used in the study was modified from that found in the literature. ${ }^{12-18}$ The classification was adjusted in order to identify as many errors as possible during the medication delivery process. In order to justify the validity of the current study's classification system for medication errors, two independent pharmacists checked the accuracy of each error identified.

The primary investigator provided clinical pharmacy services including medication reconciliation, medication chart review, clinical review, and patient discharge counseling. The investigator identified prescribing and transcription errors by reviewing patients' progress notes, their medication charts, and nurses' log books. The investigator identified dispensing and administration errors by reviewing medications dispensed from the central pharmacy in the hospital, reviewing medication charts, and checking stock levels in patients' medication drawers. The investigator also interviewed patients or their carers to identify prescribing errors (such as failure to complete patients' medication histories during admission), and to identify administration errors (eg, whether or not medications had been administered as prescribed). In the ward where the study was undertaken, the patients were attended by their family members or carer 24 hours a day. Thus, if a patient was unconscious or unable to communicate, the primary investigator obtained informed 
consent and patients' information on medication use from family members or carers.

Prescribing errors were classified as failures to prescribe regular medications on the patient's progress notes, incomplete patient medication history, and drug not prescribed although it was indicated (omission), unclear indication, wrong drug, wrong dose, wrong time, illegible hand-writing, medication duplication, unclear duration for antibiotic use, and contraindicated medication prescribed. In the study ward, the physician had to prescribe on three different documents as described previously in the "Study design and patient population" section. This resulted in transcription errors which may or may not have resulted in further errors in later steps of the medication delivery process. Transcription errors were defined as discrepancies in the medication (drug name, dose, frequencies, and dosage form [tablets/pills/syrups/injections]) written in a patient's progress notes, medication chart or drug order form, or in the nurse's log book. The nurse's log book was used as the nurse's record of administering intravenous medications (including the route, the dose, and the time).

Dispensing errors were defined as wrong dose, wrong patient, wrong drug, duplication, labeling errors, wrong dosage form (whether pills or tablets [oral], or injections [eg intravenous]), wrong quantity, drug omission, and drug dispensed although it was not charted on the drug order form. In all cases, dispensing errors were identified after the medication had arrived in ward. Administration errors were classified as administering the wrong dose, wrong drug, wrong dosage form (tablet, syrup [oral] or injections [intravenous, intramuscular]), duplicated medications, following the wrong instructions for drug administration, drug omission, drug given not indicated, and documentation errors. Documentation errors were further subcategorized into two classifications. These classifications were created during the review process because it was found that some doses of medication had not been documented although they had been given, while others had not been given but were documented as given.

Monitoring errors were identified when monitoring patients' outcomes had not been conducted, or the results of investigations were not available prior to patients being discharged. System errors included 1) errors in drug distribution (eg, three different pharmacies used to dispense medications based on patients' health insurance coverage, or stock outages); 2) errors in the health insurance system (eg, when a medication was needed by the patient but it was not covered by their insurance, or the number of medications needed exceeded the limit of the patient's health insurance coverage); and 3) technical problems (phone and facilities malfunctions).

The Anatomy and Therapeutic Chemical classification was used to classify the medications associated with medication errors. ${ }^{19}$ In addition, the World Health Organization's International Classification of Diseases Tenth Revision (ICD 10) diagnosis classification was employed to report patients' diagnoses in this study. Potential outcomes of documentation errors were classified based on the study of Lisby et $\mathrm{al}^{20}$ (Table 1$)$.

\section{Analysis of study outcomes}

The primary outcomes of this study were the nature and frequency of medication errors detected during medication delivery processes. Simple statistical analyses were employed in obtaining frequencies, means, and standard deviations. The investigator coded and evaluated each error identified

Table I Definition of potential clinical consequences

\begin{tabular}{|c|c|c|}
\hline Category & Definition & Definition of keywords \\
\hline Potentially fatal & $\begin{array}{l}\text { Medication errors judged to imply a potential } \\
\text { clinical risk for causing the death of the patient }\end{array}$ & $\begin{array}{l}\text { Fatal refers to medication errors that could lead to the } \\
\text { death of the patient }\end{array}$ \\
\hline Potentially serious & $\begin{array}{l}\text { Medication errors judged to imply a potential } \\
\text { clinical risk of injuring the patient }\end{array}$ & $\begin{array}{l}\text { Injury includes medication errors that would require } \\
\text { active treatment to restore the health of the patient. } \\
\text { A potentially serious error would lead to either } \\
\text { permanent or temporary disability }\end{array}$ \\
\hline Potentially significant & $\begin{array}{l}\text { Medication errors judged to imply a potential } \\
\text { clinical risk of being inconvenient for the } \\
\text { patient, without causing any harm or injury }\end{array}$ & $\begin{array}{l}\text { Inconvenient refers to unpleasant consequences of wrong } \\
\text { dose/drug or omission of dose/drug that could lead to } \\
\text { symptoms such as pain or dizziness. It also refers to } \\
\text { any monitoring of the patient such as extra blood tests, } \\
\text { measurement of blood pressure }\end{array}$ \\
\hline Potentially non-significant & $\begin{array}{l}\text { Medication errors judged to be without any } \\
\text { potential clinical risk for the patient }\end{array}$ & $\begin{array}{l}\text { Without clinical risk refers to medication errors that did } \\
\text { not lead to any injury or inconvenience for the patient }\end{array}$ \\
\hline
\end{tabular}

Note: Adapted from Lisby et al. Errors in the medication process: frequency, type, and potential clinical consequences. International Journal for Quality in Health Care. 2005; I (I): I5-22. By permission of Oxford University Press. ${ }^{20}$ 
during the activity based on stages of the medication delivery process. Ethical approval was obtained from the Curtin University Human Research Ethics Committee, Perth, WA, Australia (approval number HR175/2011), and from the Ethics Committee of the study hospital in Bali, Indonesia (approval number LB.02.01/II.C5.D11/4008a/2012).

\section{Results}

\section{Demographic characteristics of participants}

Ninety-two of 121 patients (76\%) who met the inclusion criteria consented to participate in the study. The participants consisted of 37 (40\%) female and 55 (60\%) male patients, with the majority in their 70 s (mean age: $71.4 \pm 7.5$ years).

Fourteen patients (15\%) were admitted because of diseases of the nervous system such as non-hemorrhagic stroke, vertigo, and epilepsy. Eleven patients (12\%) were admitted with cardiovascular diseases, and a further eleven patients $(12 \%)$ with digestive tract diseases. Eight patients $(8.7 \%)$ were admitted with both cardiovascular and renal disease. In addition, seven patients (7.6\%) were admitted with respiratory diseases such as community acquired pneumonia.

\section{Medication errors during the medication delivery process}

The 92 patients in the study were ordered a total of 770 medications, ie, 8.4 \pm 3.3 medications per patient. The

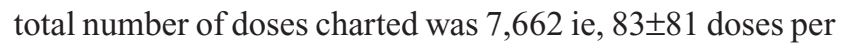
patient. A total of 1,563 medication errors were identified through the in-hospital clinical pharmacy services provided by the investigator, representing an error rate of $20.4 \%$ (1,563 errors/7,662 doses). As can be seen in Figure 1, administration errors were the most frequent medication errors identified (59.3\%), followed by transcription errors (14.7\%), dispensing errors (14.4\%), prescribing errors (6.5\%), system errors $(5.0 \%)$, and monitoring errors $(0.1 \%)$. System errors identified were related to drug distribution and health insurance issues. Errors in drug distribution included unclear procedures to obtain the medication when there was no stock in the central pharmacy. In addition, health insurance-related errors involved a different quantity of medication dispensed than ordered, in accordance with the insurance policy.

\section{Administration errors}

The majority $(64.0 \%)$ of the 927 total administration errors were associated with documentation, as shown in Figure 2. Drug omission was the second most common administration

\section{Medication errors $(\mathrm{N}=1,563)$}

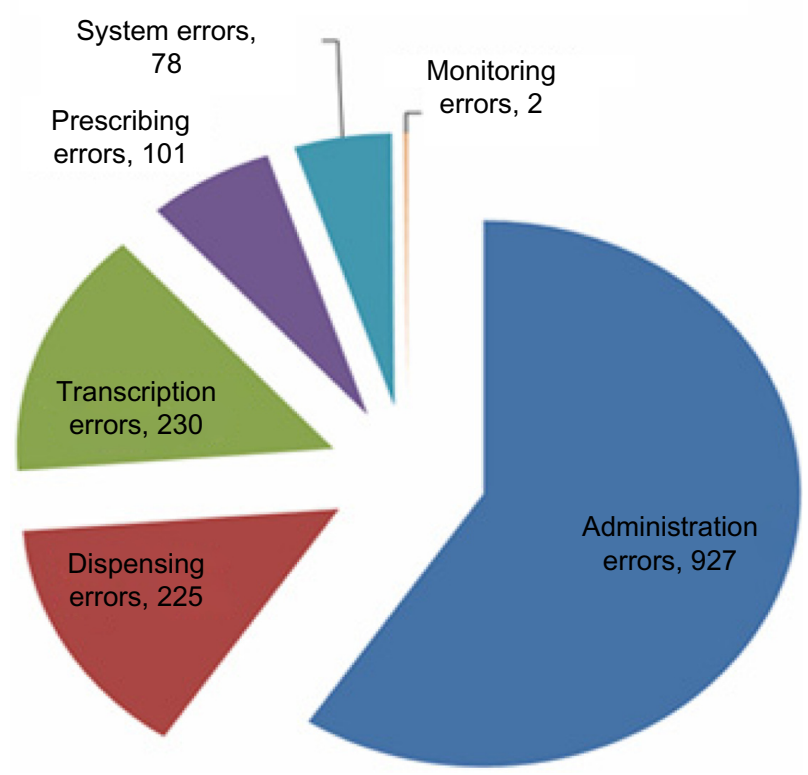

Figure I Total number of medication errors identified in the medication delivery process.

error identified (22.9\%). Pharmacist interventions during the study period prevented eight near miss events during the administration stage. These near miss events included patients potentially receiving the wrong drug or wrong dose of the right medication. For example, Humulin ${ }^{\circledR}$ insulin (Eli Lilly and Company, Indianapolis, IN, USA) was prepared to be given at a dose of 100 units more than the prescribed dose; $1 \mathrm{~g}$ of ceftriaxone was to be given instead of $2 \mathrm{~g}$, because the nurse assumed one vial contained $2 \mathrm{~g}$ instead of $1 \mathrm{~g}$; also, a dose of pantoprazole was not prepared to be administered as it had been omitted from the patient's drug regimen.

\section{Transcription errors}

The majority of the 230 total transcription errors $(35.2 \%)$ involved drugs needed by patients not being transcribed either

\section{Administration errors $(\mathrm{N}=927)$}

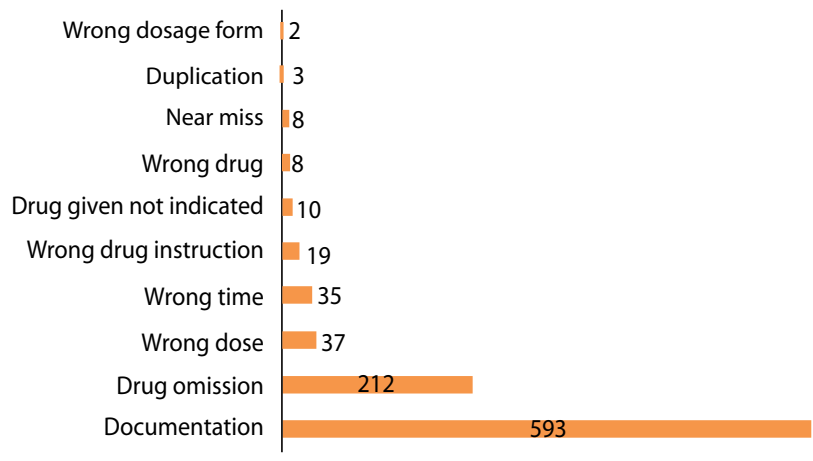

Figure $\mathbf{2}$ Types and number of administration errors identified. 
onto the medication chart or drug order form, or into the nurse's $\log$ book (Figure 3 ). These transcription errors resulted in seven drug omissions in the administration stage and two medications being given late. Valsartan, simvastatin, lansoprazole, calcium carbonate, and paracetamol were some of the medications identified in transcription errors which led to drug omission. Other transcription errors involved cessation of medications in patients' progress notes but this cessation not being reflected on their medication charts. Almost half (45\%) of medications involved in this type of transcription error were administered to the patient. Medications identified in this type of error included cefixime, paracetamol, pramipexole, captopril, lactulose, and Laxadine $^{\circledR}$ (Galenium Pharmasia Laboratories, Semarang, Indonesia). These results demonstrate the need for accuracy during the transcription process in order to avoid administration errors in the medication delivery process.

\section{Dispensing errors}

Eighty-nine (39.6\%) of 225 total dispensing errors identified during the study period were associated with omissions during the dispensing stage (Figure 4). Of these, 57 (64\%) resulted in omissions at the drug administration stage and six (6.7\%) resulted in drug administration delays. The second most common dispensing errors were labeling errors in which medications for patients were labeled incorrectly. Twenty-four near misses from dispensing errors were intercepted. The wrong dose of medication dispensed from the pharmacy was one type of near miss event detected. An example was a patient who was dispensed $2.5 \mathrm{mg}$ ramipril instead of the $5 \mathrm{mg}$ ramipril prescribed. The dispensed medication was labeled "1 tab of $2.5 \mathrm{mg}$ ramipril once daily".

\section{Prescribing errors}

The most frequent prescribing errors $(40.6 \%)$ were related to regular medications not documented in patients' progress

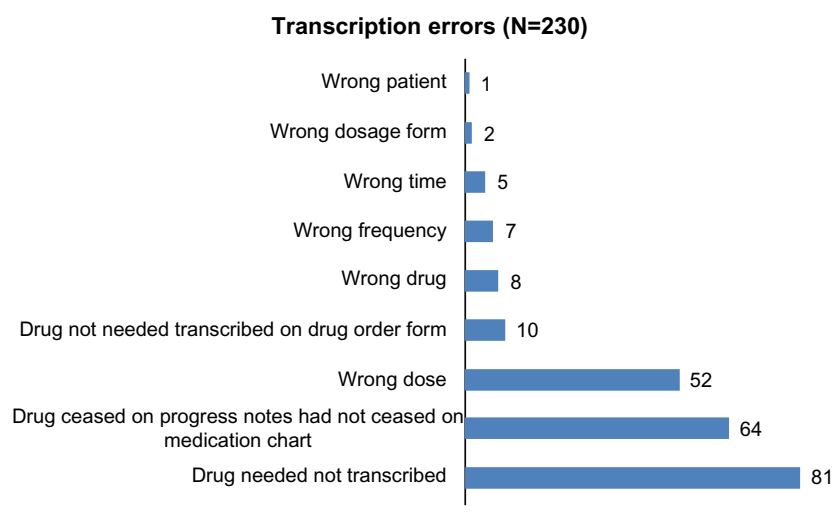

Figure 3 Types and number of transcription errors identified.
Dispensing errors $(\mathrm{N}=\mathbf{2 2 5})$

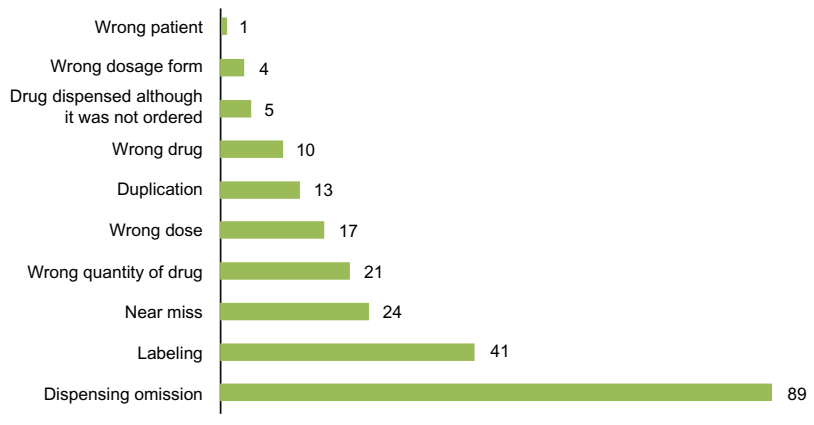

Figure 4 Types and number of dispensing errors identified.

notes (Figure 5). This type of error was followed closely in frequency by wrong dose prescribed errors. For example, a patient was prescribed both $80 \mathrm{mg}$ and $100 \mathrm{mg}$ aspirin. A review of the above patient's progress notes revealed that whilst the neurologist had prescribed $80 \mathrm{mg}$ aspirin, also written in the patient's progress notes was "aspirin $100 \mathrm{mg}$ daily". In another case, ranitidine $50 \mathrm{mg}$ injection twice daily was prescribed instead of $50 \mathrm{mg}$ three times daily as in the patient's progress notes. The third most common prescribing error was incomplete drug histories. For instance, digoxin, spironolactone, and telmisartan were identified by the pharmacist (the primary investigator) as regular medications for a patient during medication reconciliation, but these did not appear in the patient's progress notes.

\section{Documentation errors and potential outcomes}

The medications involved in documentation errors identified were classified based on the Anatomy and Therapeutic Chemical classification system ${ }^{19}$ (Table 2). Medications for

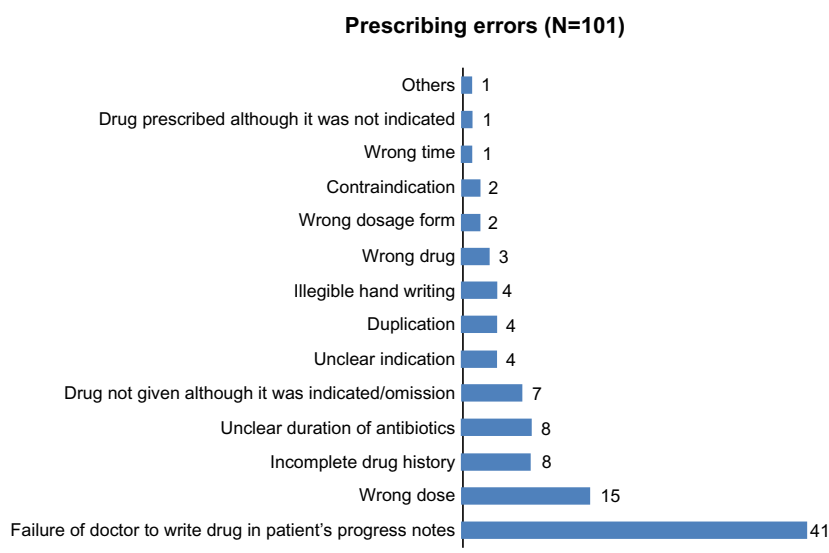

Figure $\mathbf{5}$ Types and number of prescribing errors identified. 
Table 2 Number of documentation errors identified based on Anatomy and Therapeutic Chemical (ATC) classification of medications

\begin{tabular}{lll}
\hline $\begin{array}{l}\text { ATC main group } \\
\text { classification }\end{array}$ & $\begin{array}{l}\text { Medication } \\
\text { administered but } \\
\text { not documented } \\
\text { as given }(\mathbf{N}=\mathbf{5} \text { I 3) }\end{array}$ & $\begin{array}{l}\text { Medication not } \\
\text { administered, } \\
\text { but documented } \\
\text { as given }(\mathbf{N}=\mathbf{8 0})\end{array}$ \\
\hline $\begin{array}{l}\text { Alimentary tract and } \\
\text { metabolism }\end{array}$ & 190 & 20 \\
$\begin{array}{l}\text { Cardiovascular system } \\
\text { Nervous system }\end{array}$ & 81 & 25 \\
Anti-infectives for & 54 & 13 \\
systemic use & 48 & 11 \\
Respiratory system & 40 & 2 \\
$\begin{array}{l}\text { Blood and blood-forming } \\
\text { organs }\end{array}$ & 29 & 4 \\
$\begin{array}{l}\text { Dermatologicals } \\
\text { General nutrients }\end{array}$ & 23 & - \\
Sensory organs & 19 & 1 \\
Antineoplastic and & 13 & - \\
immunomodulating agents & 9 & 2 \\
Musculo-skeletal system & 4 & - \\
Various & 3 & 2 \\
\hline
\end{tabular}

Notes: - denotes no instances of this type of documentation error 'Various' refers to multivitamins. Based on ATC classification system for the medications groups. ${ }^{19}$

the alimentary tract and metabolism, cardiovascular systems, and nervous system were the most common groups of medications that had been given but had not been documented as such on the patient's medication chart. Similarly, the same classes of medications were also the most common groups of medications which had not been administered but were documented as given.

Potential outcomes associated with documentation errors were further analyzed based on Lisby et al's classification ${ }^{20}$ (Table 3). Errors involving the failure to document administered doses $(\mathrm{N}=513)$ were all classified as potentially non-significant because the patient had in fact received the medication. Documentation errors associated with omission of doses were deemed to have a range of potential outcomes, also shown in Table 3.

All drug omissions may potentially have adverse consequences; the magnitude of such consequences depends on both the clinical status of the patient and the drug involved. Omissions of regular antihypertensive drugs, antinauseants and antiemetics, opioid analgesics, and laxatives were classified as potentially significant. This classification was applied because omission of these drugs may result in uncontrollable symptoms or disease deterioration. ${ }^{21}$ Drug omissions which involved antibacterial drugs were classified as potentially serious, because omission of antibiotic treatment may result in ineffective therapy and recurrent infection. ${ }^{21}$ Omission of antiepileptic drugs (eg, phenytoin) was also classified as
Table 3 Potential clinical outcomes of documentation errors and medication classes involved

\begin{tabular}{|c|c|c|}
\hline Category & $\begin{array}{l}\text { Errors } \\
\text { N (\%) }\end{array}$ & Identified medication groups \\
\hline Potentially fatal & 0 & Nil identified \\
\hline $\begin{array}{l}\text { Potentially } \\
\text { serious }\end{array}$ & $14(2.4 \%)$ & $\begin{array}{l}\text { Anti-infective for systemic } \\
\text { use (quinolones, beta-lactams, } \\
\text { aminoglycosides); nervous system } \\
\text { (antiepileptic drugs); blood and } \\
\text { blood-forming organs (antiplatelet and } \\
\text { anticoagulants) }\end{array}$ \\
\hline $\begin{array}{l}\text { Potentially } \\
\text { significant }\end{array}$ & $61(10.3 \%)$ & $\begin{array}{l}\text { Cardiovascular system (antihypertensive } \\
\text { drugs, lipid modifying agents); alimentary } \\
\text { tract and metabolism (drugs for peptic } \\
\text { ulcers, antinauseants and antiemetics, } \\
\text { drugs for constipation); nervous system } \\
\text { (opioid analgesics, drugs indicated for } \\
\text { analgesics and antipyretics) }\end{array}$ \\
\hline $\begin{array}{l}\text { Potentially } \\
\text { non-significant }\end{array}$ & $518(87.4 \%)$ & Vitamin and mineral supplements \\
\hline
\end{tabular}

Notes: Potentially serious outcomes were calculated from all anti-infective systemic use, I anti-epileptic drug, I antiplatelet, and I anticoagulant. Meanwhile, potentially non significant outcomes were calculated based on medication administered but not documented $(\mathrm{N}=5 \mid 3)$, plus I general nutrient, 2 various (multivitamins), and 2 immunomodulating agents.

potentially serious as such drugs should be administered on time to maintain effective blood levels ${ }^{19}$ to reduce the risk of further seizures. Similarly, omission of anticoagulants and antiplatelet agents may result in serious outcomes. ${ }^{22}$ Therefore, omissions of those medications were classified as having potentially serious outcomes.

Although the evaluation of pharmacist interventions was not the primary focus of this study, interventions were initiated. Recommendations made in the light of in-hospital clinical services provided included adjustments to the length of antibiotic use, cessation or initiation of medications, and medication dosage adjustment. Acceptance of these recommendations was lower than that reported from other studies, ${ }^{23,24}$ as indicated by an acceptance rate of $35 \%$; this low acceptance rate may reflect the unfamiliarity of the medical staff with in-hospital clinical pharmacy services in general, a lack of an established relationship between the clinicians and the pharmacist in particular, and the hierarchical nature of health care provision in Indonesia.

\section{Discussion}

To the best of our knowledge, this is the first study to document the frequency and nature of medication errors during the medication delivery process in an Indonesian hospital. This study found that administration errors were the most frequent medication errors. This might be due to the fact that nurses have high workloads. Nurses often take on the 
responsibility for transcribing medications from the patient's progress notes onto medication charts and drug order forms. They are the primary health care professional responsible for medication administration and its documentation on the ward. Furthermore, they are also required to complete patients' paperwork on admission and on discharge. These high workloads may have contributed to the high frequency of administration and transcription errors detected.

Documentation errors were the commonest type of administration error identified in this study. This is despite the fact that regulations require two nurses to check medications. According to Ferner and Aronson, ${ }^{25}$ documentation errors related to drugs given but not documented are associated with memory lapses (memory-based errors). In addition, documentation errors where medications have not been given but are documented as given are rules-based errors. Medication administration should only be documented after the medication has been given, not before or when it is planned to be given. Thus, these documentation errors relate to a failure to follow the correct procedures during the medication delivery process. Clear, accurate, complete, and timely documentation is important for several reasons. Accurate documentation ensures the quality of health care service delivered. Accurate and complete documentation can be used to defend health care professionals against malpractice. ${ }^{26} \mathrm{Clear}$ and timely documentation is also important for the sake of researchers and health organizations, because it serves as reliable evidence to evaluate the quality of health care services provided. ${ }^{26}$

Medications not being transcribed onto the medication charts or drug order forms were the most frequent transcription errors identified. These transcription errors were highly influenced by the hospital documentation system. In the current system, the physician has to write patients' medications in three different documents (the patient's progress notes, medication chart, and the drug order form). The investigator identified transcription errors when reconciling patients' regular medications. In these cases, regular medications were charted but they were not prescribed on patients' progress notes. In this type of error scenario, physicians mistakenly did not note regular patients' medications in their progress notes. This lapse quite often resulted in other health professionals (nurses or pharmacists) having different assumptions regarding patients' regular medications. This could be seen when the investigator found discrepancies between patients' progress notes and medication charts, and subsequently queried the nurse in charge as to which document was correct. According to Dean et al. ${ }^{15}$ this type of error is associated with prescription writing processes. Similar to documentation errors discussed previously in this section, this error type is also related to rules-based mistakes according to Ferner and Aronson's classification of medication errors. ${ }^{25}$ These findings demonstrate poor quality assurance in the studied institution's health care service delivery.

In the study hospital, three different pharmacies provided medication to the ward depending upon a patient's health insurance coverage. This created major issues in medication administration, particularly when there was no stock in the central pharmacy or when a medication prescribed was not covered by patients' health insurances. Systems issues related to drug distribution and health insurance systems contributed to 78 medication errors. Sometimes, these errors caused additional errors in the administration process. This demonstrates that poor procedures in the drug distribution system and/or a lack of communication between the central pharmacy and the ward contributed to medication errors. To minimize drug omission errors arising through the dispensing process, it is suggested that drug distribution should be streamlined, with the central pharmacy distributing medication to satellite pharmacies on wards, with the satellite pharmacies to take responsibility for all drugs supplied.

This study demonstrated that medication errors may occur in every stage of the medication delivery process. Different health care professionals have different roles during this process and hence, they may commit different types of medication errors. In addition, failures such as those associated with drug distribution and health insurance, may also lead to errors. The main limitation of this study was that only one ward in one hospital was included; thus, the generalizability of the results may be limited. Further, the presence of the primary investigator on the ward may have affected the behavior of the other health care professionals, particularly when questions were asked about discrepancies, and recommendations were made to address actual errors and near misses. Finally, the validity of some documentation errors reported in this study was highly dependent on the information retrieved from nurses and patients, because the investigator was unable to observe all functions of medication administration.

Medication errors are preventable events; thus, understanding the nature of errors during the medication delivery process may potentially improve health care services through the implementation of strategies to prevent the same errors from occurring again. However, there is no simple solution to preventing medication errors during the medication delivery process. Based on the findings of the current study, simplification of the medications ordering process, with removal of 
the need for both medication charts and drug order forms, would appear to be a means of reducing the number of omissions and transcription errors. The implementation of a comprehensive computerized medication orders system would provide a more comprehensive solution. In the late 1900s, research demonstrated that Computerized Physician Ordered Entry (CPOE) reduced medication errors. ${ }^{27}$ However, recent evidence shows that CPOE potentially contributes to other technical errors. ${ }^{28}$ Furthermore, CPOE requires information and technology maintenance which is costly, and requires health care providers to have sufficient computer literacy skills to effectively utilize the system. Thus, implementing CPOE in the study hospital is likely not a viable solution.

Errors in documentation and transcription could be minimized by involving pharmacists during the medication process. Pharmacists potentially play an important role in reducing medication misadventures through the delivery of in-hospital clinical pharmacy services including medication reconciliation, ${ }^{29}$ medication chart review, clinical review, staff education, and patient discharge counseling. Medication reconciliation is an activity that ensures the continuity of medications used during transfers between wards, or before and after hospitalization. The Joint Commission $^{30}$ defines medication reconciliation as "the process of comparing the medications a patient is taking with newly ordered medication". Although methodological issues exist in assessing the impact of pharmacists' interventions on medication safety, the Agency for Healthcare and Research Quality ${ }^{31}$ suggested that pharmacists' involvement reduces adverse drug events, particularly preventable events (eg, medication errors).

Pharmacists' involvement in ensuring medication safety requires support from the health care system, health administrators, and a good practice environment. Currently, the role of pharmacists in medication safety in hospitals in Indonesia is very limited, as pharmacists are generally involved in drug distribution and not in the provision of patient-related services. This study suggests that pharmacists, through the provision of in-hospital clinical pharmacy services, could potentially play a significant role in detecting and preventing medication errors.

\section{Disclosure}

The authors report no conflicts of interest in this work.

\section{References}

1. Guchelaar HJ. Medication errors: hospital pharmacist perspective. Drugs. 2005;65(13):1735-1746.
2. McDonald A, Leyhane T. Drill down with root cause analysis. Nurs Manage. 2005;36(10):26-31.

3. Aspden P, Wolcott JA, Bootman JL, Cronenwett LR, editors. Preventing Medication Errors: Quality Chasm Series. Washington, DC: National Academies Press; 2006.

4. Lisby M, Nielsen LP, Brock B, Mainz J. How are medication errors defined? A systematic literature review of definitions and characteristics. Int J Qual Health Care. 2010;22(6):507-518.

5. National Coordinating Council for Medication Error Reporting and Prevention. What is a Medication Error? 2013 Available from: http://www. nccmerp.org/aboutMedErrors.html. Accessed November 20, 2013.

6. Pintor-Mármol A, Baena MI, Fajardo PC, et al. Terms used in patient safety related to medication: a literature review. Pharmacoepidemiol Drug Saf. 2012;21(8):799-809.

7. Reason J. Human Error. New York: Cambridge University Press; 1990.

8. Leape LL, Bates DW, Cullen DJ, et al. Systems analysis of adverse drug events. ADE Prevention Study Group. JAMA. 1995;274(1): $35-43$.

9. Croteau RJ, editor. Root Cause Analysis in Health Care: Tools and Techniques. 4th ed. Oakbrook Terrace (IL): Joint Commision Resources; 2010.

10. Alfansi L, Atmaja FT. Service failure and complaint behaviour in the public hospital industry: the Indonesian experience. J Nonprofit Public Sector Market. 2009;21(3):309-325.

11. Perwitasari DA, Abror J, Wahyuningsih I. Medication errors in outpatients of a government hospital in Yogyakarta Indonesia. Int $J$ Pharm Sci Rev and Res. 2010;1(1):8-10.

12. Williams D. Medication errors. J R Coll Physicians Edinb. 2007;37(4): 343-346.

13. American Society of Hospital Pharmacists, editor. ASHP guidelines on preventing medication errors in hospitals. Am J Hosp Pharm. 1993;50(2):305-314.

14. Protocare Sciences. Addressing Medication Errors in Hospitals: Ten Tools. California Healthcare Foundation; 2001. Available from: https:// www.premierinc.com/safety/topics/bar_coding/downloads/addressingmederrorstentools/. Accessed October 16, 2011.

15. Dean B, Barber N, Schachter M. What is a prescribing error? Qual Health Care. 2000;9(4):232-237.

16. James KL, Barlow D, McArtney R, Hiom S, Roberts D, Whittlesea C. Incidence, type and causes of dispensing errors: a review of the literature. Int J Pharm Pract. 2009;17(1):9-30.

17. Beso A, Franklin BD, Barber N. The frequency and potential causes of dispensing errors in a hospital pharmacy. Pharm World Sci. 2005;27(3): 182-190.

18. Bohand X, Simon L, Perrier E, Mullot H, Lefeuvre L, Plotton C. Frequency, types, and potential clinical significance of medicationdispensing errors. Clinics (Sao Paulo). 2009;64(1):11-16.

19. WHO Collaborating Centre for Drug Statistics Methodology. Guidelines for ATC classification and DDD assignment 2013. Oslo: World Health Organization; 2012. Available from: http://www.whocc.no/filearchive/ publications/1_2013guidelines/. Accessed October 7, 2013.

20. Lisby M, Nielsen LP, Mainz J. Errors in the medication process: frequency, type, and potential clinical consequences. Int $J$ Qual Health Care. 2005;17(1):15-22.

21. Workman ML, LaCharity LA, Kruchko SL. Understanding Pharmacology: Essentials for Medication Safety. St Louis (MI): Elsevier Saunders; 2011.

22. National Reporting and Learning Service. Reducing Harm from Omitted and Delayed Medicines in Hospital: Rapid Response Report NPSA/2010/RRR009. National Patient Safety Agency; 2010. Available from: http://www.nrls.npsa.nhs.uk/alerts/?entryid45=66720. Accessed December 10, 2013.

23. Fernández-Llamazares CM, Calleja-Hernandez MA, ManriqueRodriguez S, Pérez-Sanz C, Duran-García E, Sanjurjo-Saez M. Impact of clinical pharmacist interventions in reducing paediatric prescribing errors. Arch Dis Child. 2012;97(6):564-568. 
24. Barber ND, Batty R, Ridout DA. Predicting the rate of physicianaccepted interventions by hospital pharmacists in the United Kingdom. Am J Health Syst Pharm. 1997;54(4):397-405.

25. Ferner RE, Aronson JK. Clarification of terminology in medication errors: definitions and classification. Drug Saf. 2006;29(11):1011-1022.

26. Association for Healthcare Documentation Integrity. Healthcare Documentation Quality Assessment and Management Best Practices. 2010 [updated Mar 2010]. Available from: http:/www.ahdionline.org/ LinkClick.aspx?fileticket=f3sQg96ixiQ\%3D\&tabid=601. Accessed March 21, 2013.

27. Bates DW, Teich JM, Lee J, et al. The impact of computerized physician order entry on medication error prevention. J Am Med Inform Assoc. 1999;6(4):313-321.

28. Koppel R, Metlay JP, Cohen A, et al. Role of computerized physician order entry systems in facilitating medication errors. JAMA. 2005;293(10):1197-1203.
29. American Society of Health System Pharmacists. ASHP statement on the pharmacist's role in medication reconciliation. Am J Health Syst Pharm. 2013;70(5):453-456.

30. The Joint Commision. Sentinel Event Alert, Issue 35: Using Medication Reconciliation to Prevent Errors. The Joint Commission; 2006. Available from: http://www.jointcommission.org/assets/1/18/SEA_35. PDF. Accessed December 8, 2013.

31. Rand Corporation. Making Health Care Safer II: An Updated Critical Analysis of the Evidence for Patient Safety Practices. Santa Monica: Agency for Healthcare Research and Quality; 2013. Available from: http://www.ahrq.gov/research/findings/evidence-based-reports/ ptsafetyuptp.html. Accessed December 8, 2013.

\section{Publish your work in this journal}

Therapeutics and Clinical Risk Management is an international, peerreviewed journal of clinical therapeutics and risk management, focusing on concise rapid reporting of clinical studies in all therapeutic areas, outcomes, safety, and programs for the effective, safe, and sustained use of medicines. This journal is indexed on PubMed Central, CAS,
EMBase, Scopus and the Elsevier Bibliographic databases. The manuscript management system is completely online and includes a very quick and fair peer-review system, which is all easy to use. Visit http://www.dovepress.com/testimonials.php to read real quotes from published authors.

Submit your manuscript here: http://www.dovepress.com/therapeutics-and-clinical-risk-management-journal 